\title{
A Bicycle Design Model Based on Young Women’s Fashion Combined With CAD and Statistical Science
}

\author{
Kaori Koizumi, Shinji Kawahara, Yuki Kizu, Kakuro Amasaka \\ Aoyama Gakuin University, Kanagawa, Japan
}

\begin{abstract}
Today, more people are riding bicycles than ever before-and the numbers keep growing. This is due in part to a greater awareness of environmental issues and growing health consciousness. Another factor driving the increasing number of women bicyclists today is many designer bicycles now available. Still, these bicycles reflect the subjective sensibilities of their designers, and there is no guarantee that they will always match an increasingly diverse array of consumer values. In response to this challenge, our study sets out to build a bicycle design model based on fashion styles popular with young women in their 20s. Fashion analysis and bicycle design analysis used statistical science, such as cluster analysis, principal component analysis, and analytic hierarchy process (AHP). After that, we designed a new bicycle using computer-aided design (CAD) from the analysis results. Finally, the approach model developed in this study was confirmed to be effective by an interview with the company.
\end{abstract}

Keywords: young women's fashion, bicycle design model, desire words

\section{Introduction}

Today, more people are riding bicycles than ever before-and the numbers keep growing. This is due in part to a greater awareness of environmental issues and growing health consciousness. Another factor driving the increasing number of women bicyclists today is many designer bicycles now available. Still, these bicycles reflect the subjective sensibilities of their designers, and there is no guarantee that they will always match an increasingly diverse array of consumer values. It goes without saying that bicycles are built in a way that reflects the times.

As consumer values continue to diversify, it is becoming increasingly critical that bicycles express a concept and design that appeal to customer sensibilities. In past eras, where buyers were looking primarily for functionality, product designers could focus on the concept of "getting a product out"-meaning simply building a product with minimum functionality and knowing it would sell. Today, when it has become increasingly difficult for products to distinguish themselves in terms of function or performance, manufacturers cannot sell their products unless they offer customers what they truly want.

This represents a complete shift to the idea of "customer delight", a concept requires that product designers grasp social trends. In order to achieve this "customer delight”, manufacturers must focus on finding

Kaori Koizumi, Graduate Student, School of Science and Engineering, Aoyama Gakuin University.

Shinji Kawahara, Graduate Student, School of Science and Engineering, Aoyama Gakuin University.

Yuki Kizu, Graduate Student, School of Science and Engineering, Aoyama Gakuin University.

Kakuro Amasaka, Ph.D., Professor, School of Science and Engineering, Aoyama Gakuin University.

Correspondence concerning this article should be addressed to Kakuro Amasaka, 5-10-1, Fuchinobe, Chuo-ku, Sagamihara-shi, Kanagawa-ken, 252-5258, Japan. E-mail: kakuro_amasaka@ise.aoyama.ac.jp. 
ways to identify what customers are thinking, and then figure out how to make the best use of that knowledge. "What customers are thinking" is another way of saying "customer feedback", and it is essential that product developers approach the concept of "customer science" with a focus on feedback and careful consideration of consumer values.

Objectively grasping customer preferences and values and then building them into the design process to express them in a concrete way is a critical element of product design strategy —and also makes it possible to predict what bicycle styles will sell 10, 20, or even more years down the line chances of achieving their goals in real-life cases and provide confidence ratings in their predictions (Koizumi, Kawahara, \& Kizu, 2011).

\section{Background}

The mission of a manufacturer is to offer products the consumers (customers) are pleased with, as the basis for sustainable growth. Entering into a new century of product creation based on the management of global marketing, it is necessary to create the kind of products which further enhance the life stages and lifestyles of customers, as well as customer value. In order to develop and offer attractive, customer-oriented products, it is vital to urgently and seriously consider "customer needs" and to establish strategic product development methods which are ahead of the times (Amasaka, 2005).

In order to directly confront the management environment today's companies are surrounded by and to implement the necessary measures to respond to it, it is indispensable to establish a "scientific approach toward customer orientation”. A reasonable business approach is needed which can be utilized for product planning and technical development through the digitization of the hidden desires of customers, so that subjective information (about the customers) and objective information (objectified by technology) can be mutually and compatibly exchanged.

Generally speaking, though customers have both favorable and unfavorable evaluations about current products in the market, they usually do not have a clear image of what types of products they want in the future. The customers express their demands in spoken words, and therefore the product designers (planning and designing staff) need to accurately interpret such expressions and convert them into corresponding design drawings.

For this reason, the sales and service staff who are closest to the customers need to express the product image that the customers have to the planners (research engineers/designers who think objectively in numerical terms) who engage in product development, in a scientific, common language rather than rely on an implicit, vague language (Amasaka, 2009a). In connection with the creation of future products, it is particularly important to "offer precisely and quickly what the customers want before they realize they want it".

In order to do this, it is vital to clearly grasp the hazy, ambiguous feelings of customers. The "product development technological method-customer science" (Amasaka, 2002a, 2008a) shown in Figure 1 is what gives concrete shape to such customer wants. It is intended to present a model of (an approach to) a new business process for creating "wants" which is indispensable for manufacturing attractive products.

As depicted in Figure 1, so-called objectification of subjectivity wherein the image of customers' words (implicit knowledge) is expressed in a common language (lingual knowledge) and then, by incorporating technical words (design drawings, etc.) as well as correlation techniques, it is further interpreted appropriately (into explicit knowledge). When using the methodology of customer science for approaching various customer-related situations, such as why the customers are satisfied or dissatisfied with a particular product, 
what is the underlying feeling behind a certain expression, what kind of products then need to be offered, or in what specific situation a recall case occurs, the situations can then be interpreted into a common language, and further converted into the language of technology.

Then the staff of the research and development or designing departments can digitize such situations by means of correlation techniques utilizing statistical science, simulate them in the laboratory or experiment facility, and confirm the conditions in which such situations are most likely to occur. Finally, it is necessary to check whether what is represented on a drawing specifically reflects what the customers actually want and thereby confirm the accuracy of the work being performed, thus subjectifying the objectivity using correlation techniques (Amasaka, Nagoya, \& Shibata, 1999; Amasaka, 2002b, 2003, 2007a).

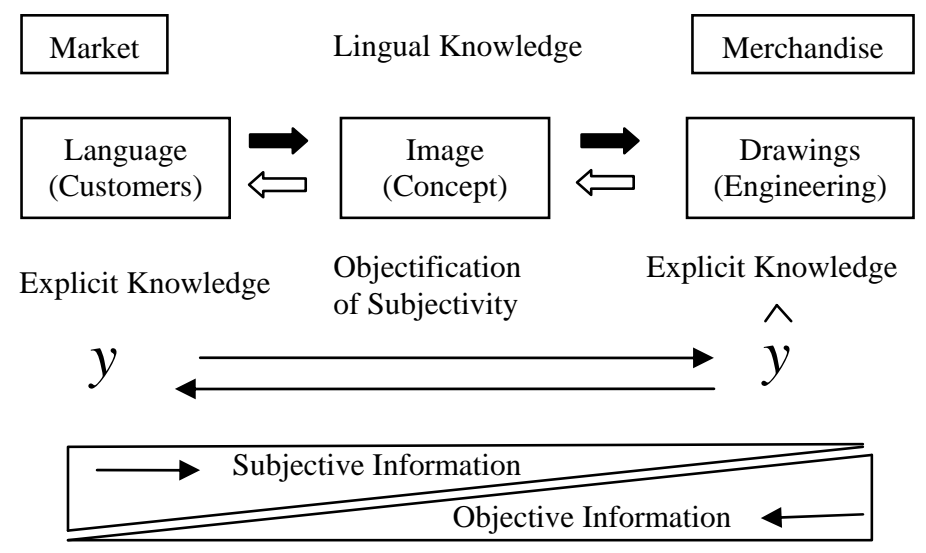

Figure 1. Schematic drawing of customer science.

By conducting "total marketing", that is, an approach focusing on "quality management that gives customers top priority" incorporating customer science, the implicit business process, consisting of promotion/sales, product planning, designing, development designing, and production, which has been a major concern for the management class, can be clarified further. By means of the scientific knowledge obtained from the cycle of these business processes, "accumulation of successes" or "correction of failures" can be carried out more accurately than ever, and therefore highly reliable quality management, "scientific quality management" can definitely be realized (Amasaka, Watanabe, \& Shimakawa, 2005).

It is observed that well-performing manufacturers both inside and outside Japan today have maintained an attitude which prompts them to humbly repeat the process of clarifying implicit knowledge in order to grasp the customers' feelings to the greatest extent possible, and then feed it back to check whether what is reflected in their product design drawings truly represents the objectified demands of customers. Such an attitude constitutes the basis of their manufacturing activity (Amasaka, 2007b, 2007c, 2008b, 2009b).

This approach is common to Statistical Quality Control (SQC) introduced to Japan by Dr. Shewhart and Dr. Deming and has immensely contributed to postwar Japanese manufacturing and the development of quality management technology (Shewhart, 1986; Mary, 1988; Joiner, 1994; Gabor, 1990).

\section{A New Bicycle Design Approach Model}

We have seen that bicycle designs currently rely on the subjective sensibilities of bicycle designers. In this study, we outline a series of five steps that take the tacit knowledge underlying bicycle design (the intuition and 
personal skills that designers have) and making it explicit with the help of preference factors and preference studies. This process allows manufacturers to offer bicycle designs that match the sensibilities of their target consumers (Koizumi et al., 2012a).

\section{Preliminary Survey $<$ STEP0 $>$}

First, examine prior research. Conduct a company market survey to better understand today's bicycle industry, the tastes and preferences of the target buyers (women in their 20s), and the challenges and conditions affecting bicycles in general.

\section{Identify Focal Areas $<$ STEP1 $>$}

Use an eye-tracking camera to identify what parts of a bicycle women in their 20s focus their attention on.

\section{Fashion Analysis <STEP2 $>$}

Use the results of the preliminary survey and street survey to put together a collage. Analyze the results from preference studies and group them into five style systems by preference. Narrow down the target buyers and identify bicycle "desire words" from the target women.

\section{Bicycle Design Analysis $<$ STEP3 $>$}

Determine the shape of the frame of the bicycle, color, and color of the tire from preference studies and desire words extracted in STEP2.

\section{Create a Design $<$ STEP4 $>$}

Use the analysis results collected thus far to create an actual design using CAD.

\section{Approach a Design Model <STEP5>}

Propose a bicycle design approach model and verify the results.

\section{Identify Focal Areas}

Bicycles have many different parts, and it is not clear which of these impact design evaluations. To resolve this difficulty, we used an eye-tracking camera to analyze line of sight and identify which parts women pay the most attention to. This allowed us to identify the parts that received the most attention as those that have the greatest impact on design evaluations. The study itself was done by having test subjects look at images of women on bicycles and evaluate them. Starting with the heat map in Figure 2, we see that subjects paid the most attention to the style of the bicycle and to the frame.

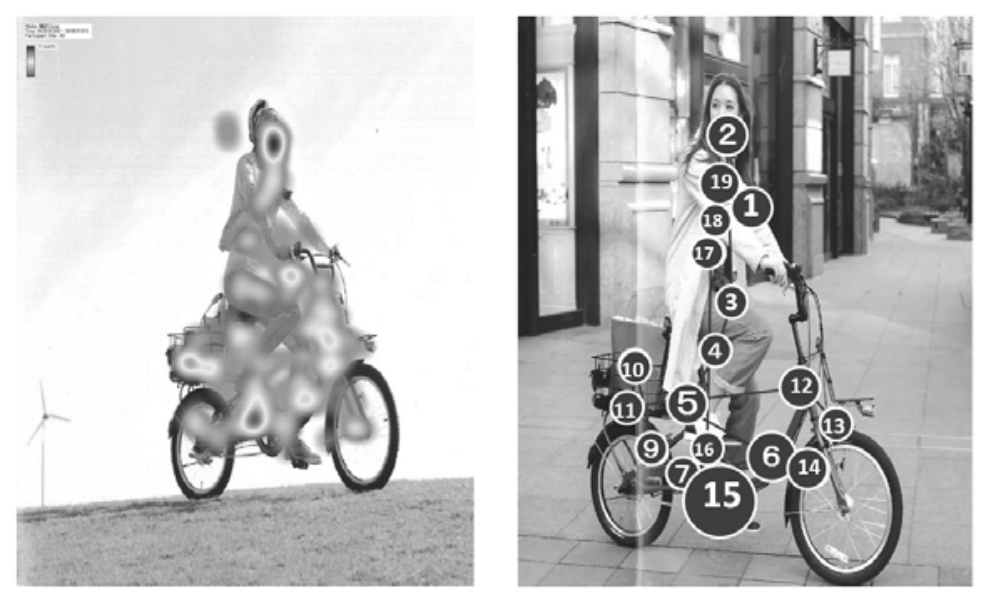

Figure 2. Heat map and gaze map. 
The thing they looked at next was the tires. Moving on to the gaze map in Figure 2, we see that subjects were more interested in the style, form, and tires (in that order). This indicates a relationship between these three areas. Using these two insights, we noted the focus on style and the frame and reconfirmed the importance of taking style into account when designing a bicycle. After learning that the aspects of the bicycle that have the most impact are the frame, the style, and the tires, we conducted the following analysis with a focus on these three points.

\section{Fashion Analysis}

\section{Create a Collage}

Our study grouped women in their 20s into style groups based on their image of bicycles. These groupings were then used to analyze the design preferences of target buyers, outline what needed to be done to generate a design concept, and actually create a bicycle design. A collage was then created based on the results of the preference studies. In order to decide what form of media to use in creating the collage, preference study participants were asked, “What sources do you consult when buying clothes?”-magazines. From this, we concluded that women in their 20s use magazines to inform their purchases and construct their fashion styles. Figure 3 groups magazines by style category.

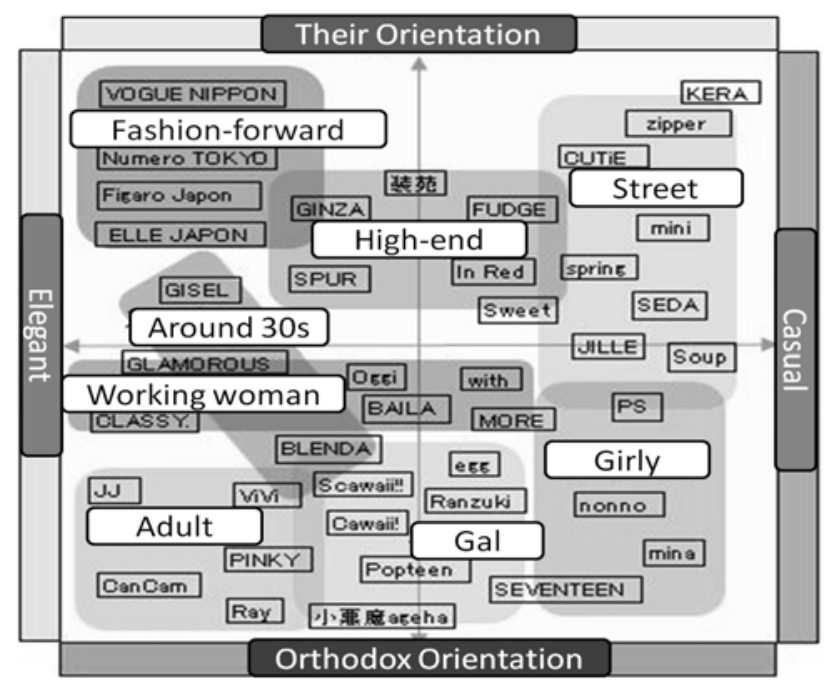

Figure 3. The positioning map of magazines.

The items that subjects chose as best representing a particular style as shown in Figure 4 were used to create the collage. These items are either frequently worn or carried by women, and include clothing, shoes, watches, bags, and wallets.

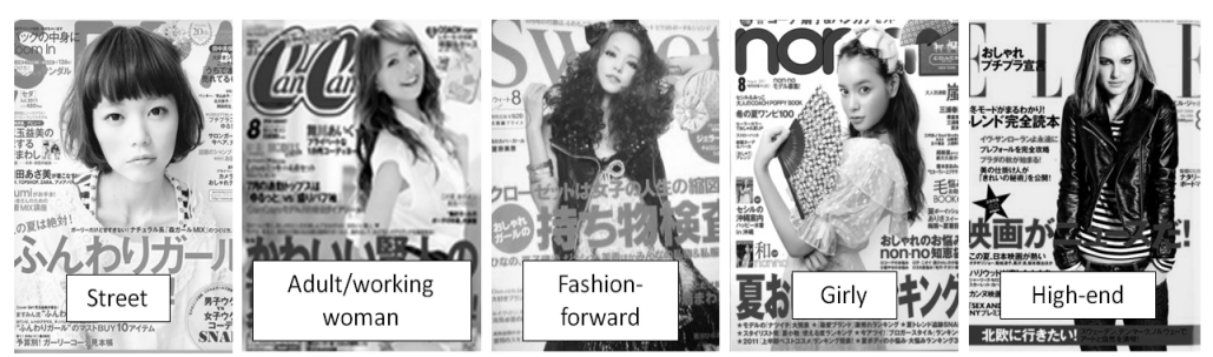

Figure 4. Fashion magazines—each of the decisions. 
Each fashion style was defined using the collage shown in Figure 5.

- Girly: A style characterized by cute, girlish tastes;

- Fashion-forward: An edgier style in line with cutting-edge fashion trends;

- Adult/working woman: A more mature, classic feminine style;

- High-end: A style that skillfully incorporates top fashion labels to flatter individual shape;

- Street: A relaxed, casual fashion style that incorporates some girly elements.

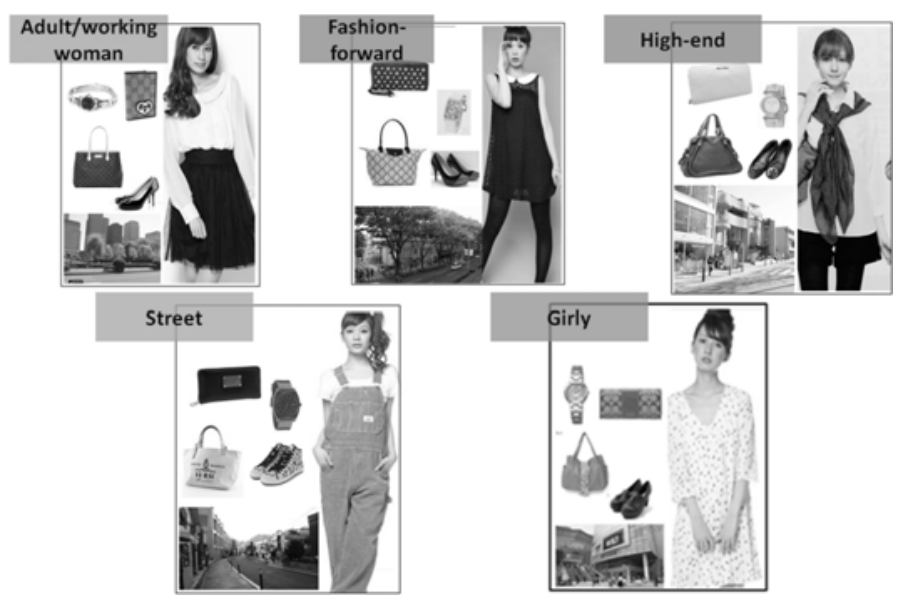

Figure 5. Collage.

\section{Extract Desire Words of the Bicycle}

We started by performing a cluster analysis of the response data from the preference surveys to identify respondent preferences. Women in their 20s were clustered into five different groups based on their responses to the preference study question "What is important to you when purchasing a bicycle?" as shown in Figure 6.

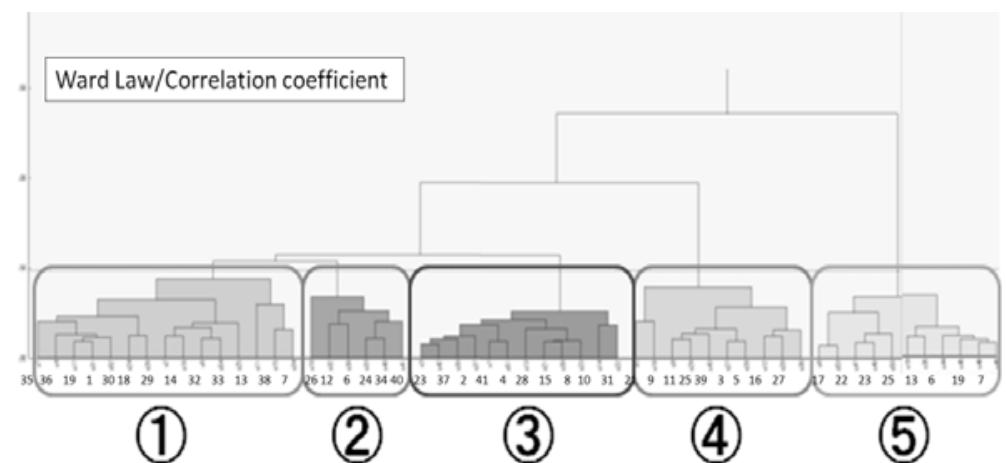

Figure 6. Classification of preference by cluster analysis. Group 1: Design-focused; Group 2: Brand-focused; Group 3: Disinterested; Group 4: Trend-focused; and Group 5: Price-focused.

Next, the following determinations were made based on a positioning map that groups the magazines in Figure 3 by fashion style (these were the magazines indicated in the analysis results and those that participants said they read during the preference survey). Based on the above research on bicycle design, we selected the Group 1/Girly group as the target for this study. Next, a principal component analysis study was conducted on the same response results to create a positioning map.

When we gather around the variables with a correlation coefficient of at least 0.5 on the vertical axis, principal component 1 in the factor loadings is positive "unique”, "urban”, “cute”, and "futuristic", we have 
found that the correlation and "orthodox" have a negative correlation. We found out that as well, "a positive correlation”, "orthodox", and "classic 2 main component” are "rare” and negative correlation.

In addition, the component of the principal component scores, it clarified that principal component 1 has a strong positive correlation sample $8,10,47,48$, and 53 . On the other hand, negative correlation is sample 5,12 , 18, and 36. We found out as well, principal component 2 found to be positive correlation is sample 15, 47, and 48 and negative correlation is sample 10, 24, 33, and 38. It can be said from these results, the axis of principal component 1 is "axis representing the design of the bicycle", the axis of principal component 2 is "axis representing the approach to the bicycle".

The information in Tables 1 and 2 was used to come up with bicycle "desire words" for women in the "girly" style category: urban, cute, and futuristic/fresh. We categorized by fashion group, a scatter plot of principal components: principal component 1 and principal component 2.

Table 1

Factor Loadings

\begin{tabular}{lccccc}
\hline $\begin{array}{l}\text { Variable } \\
\text { name }\end{array}$ & Principal component 1 & Principal component 2 & Principal component 3 Principal component 4 Principal component 5 \\
\hline Orthodox & -0.133 & 0.729 & 0.187 & -0.026 & -0.372 \\
Futuristic & 0.808 & -0.162 & -0.022 & -0.062 & -0.232 \\
Unusual & 0.139 & -0.327 & 0.808 & -0.412 & -0.023 \\
Individual & 0.569 & 0.339 & 0.325 & -0.056 & -0.033 \\
Classic & 0.173 & 0.733 & -0.121 & -0.477 & -0.232 \\
Noticeable & 0.267 & 0.425 & 0.342 & 0.661 & -0.402 \\
Urban & 0.676 & -0.355 & 0.107 & 0.210 & 0.366 \\
Cute & 0.800 & -0.247 & -0.143 & -0.043 & -0.148 \\
Elegant & 0.776 & 0.047 & -0.317 & -0.183 & \\
\hline
\end{tabular}

Table 2

Principal Component Analysis

\begin{tabular}{|c|c|c|c|c|c|}
\hline Sample & $\begin{array}{l}\text { Principal } \\
\text { component } 1\end{array}$ & $\begin{array}{l}\text { Principal } \\
\text { component } 2\end{array}$ & $\begin{array}{l}\text { Principal } \\
\text { component } 3\end{array}$ & $\begin{array}{l}\text { Principal } \\
\text { component } 4\end{array}$ & $\begin{array}{l}\text { Principal } \\
\text { component } 5\end{array}$ \\
\hline 1 & 0.042 & -1.323 & -1.155 & -1.066 & -0.922 \\
\hline 2 & 0.576 & -0.412 & -0.234 & -0.578 & 0.310 \\
\hline 3 & 0.241 & -1.188 & 0.025 & 0.652 & 0.254 \\
\hline 4 & -0.302 & -0.405 & -1.137 & 0.909 & 0.300 \\
\hline 5 & -2.540 & 0.924 & -1.694 & -0.547 & -0.227 \\
\hline 6 & -0.256 & -0.225 & -0.150 & 1.523 & -1.018 \\
\hline 7 & -0.124 & -0.588 & 0.423 & -0.044 & 0.838 \\
\hline 8 & 1.846 & 0.167 & -0.551 & 0.546 & -0.360 \\
\hline 9 & -0.960 & 0.344 & -1.070 & -0.921 & 0.836 \\
\hline$\ldots$ & $\ldots$ & $\ldots$ & $\ldots$ & $\ldots$ & $\ldots$ \\
\hline 45 & 0.982 & 1.156 & 1.130 & -0.192 & -1.061 \\
\hline 46 & 1.240 & 1.049 & 1.051 & -0.550 & 0.158 \\
\hline 47 & 1.692 & 1.864 & 0.068 & 0.054 & -0.743 \\
\hline 48 & 1.534 & 1.908 & 0.441 & -0.647 & 0.295 \\
\hline 49 & 0.942 & 1.048 & 1.482 & -0.367 & 0.232 \\
\hline 50 & 1.409 & 1.536 & -1.398 & 0.645 & -0.073 \\
\hline 51 & -0.424 & -0.806 & 0.887 & -0.478 & 0.482 \\
\hline 52 & 0.134 & -0.077 & -2.263 & 0.854 & -0.217 \\
\hline 53 & 1.897 & -0.107 & 0.334 & 1.138 & -0.521 \\
\hline 54 & -0.029 & 0.555 & -0.739 & 0.319 & -0.494 \\
\hline
\end{tabular}


The information in Figure 7 was used to come up with bicycle "desire words" for women in the "girly" style category: urban, cute, and futuristic. Using the eye-tracking camera measurements recorded in STEP 1 and the fashion analysis results from STEP 2, we altered bicycle frame shape, frame angle/height, frame color, and tire color and had women in the "girly" style category score each one using a 7-point scale. We then subjected the results to an Analytic Hierarchy Process (AHP analysis).

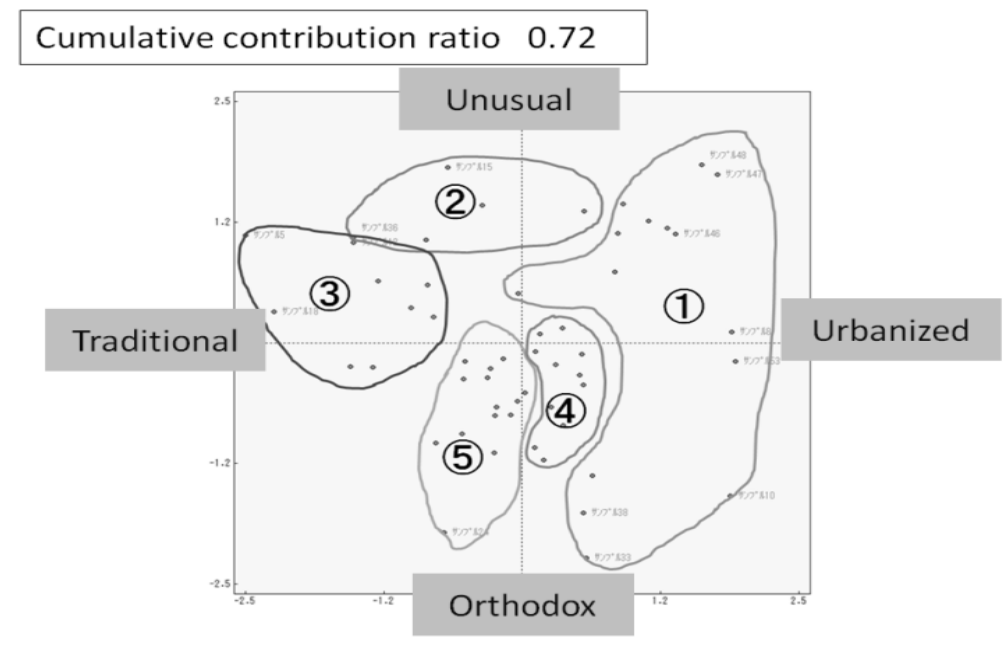

Figure 7. Scatter plot.

\section{Bicycle Design Analysis}

\section{Frame Shape}

For frame shape, we conducted a preference study on five typical shapes for the small-wheel bicycles used in this study. Bicycle frame-shaped decision is analyzed by using the AHP and preference survey. The alternative with the highest severity grade point method seven, three elements each of the "futuristic", "urban", and "cute" type bicycle frame five is the result of research, taking the maximum value of their elected. Table 3 is the degree of importance of each of the futuristic, urban, and cute. First, calculated when determining the frame shaped or which word to emphasize how much desired in the futuristic, urban, and cute. The result is shown in Table 3.

\begin{tabular}{|c|c|}
\hline $\begin{array}{c}\text { Type name } \\
\text { Diamond- } \\
\text { shaped }\end{array}$ & Picture \\
\hline $\begin{array}{c}\text { Staggered- } \\
\text { shaped }\end{array}$ \\
\hline Mikisto-shaped \\
\hline Loop-shaped \\
\hline U-shaped
\end{tabular}

Figure 8. Typical frame types of the small-wheel bicycles.

As an alternative set of five different frames shaped, each alternative had evaluated by seven points in a futuristic, urban, and cute. An example of the results for "cute" as can be seen in Table 4. After that, perform the calculation of the degree of importance as well. 
Table 3

Extraction of the Bicycle Frame Shaped (Degree of Desire Words)

\begin{tabular}{lllll}
\hline Desire words/Sample & Cute & Urban & Futuristic & Total \\
\hline 1 & 7 & 6 & 5 & \\
2 & 7 & 6 & 4 & \\
3 & 7 & 6 & 4 & \\
4 & 6 & 7 & 4 \\
5 & 7 & 6 & 5 & \\
6 & 6 & 7 & 5 & \\
7 & 5 & 7 & 4 & \\
8 & 5 & 7 & 6 & \\
9 & 7 & 5 & 6 & 17.58 \\
10 & 7 & 5 & 6 & 1.00 \\
11 & 7 & 6 & 6 & 4.92 \\
12 & 7 & 6 & 0.28 & \\
Average & 6.5 & 6.17 & 0.35 & \\
Degree of importance & 0.37 & &
\end{tabular}

Table 4

Alternative of the Bicycle Frame Shaped (Cute)

\begin{tabular}{|c|c|c|c|c|c|c|}
\hline Alternative/Sample & Mixed shaped & Diamond shaped & Staggered shaped & Loop shaped & U-shaped & Total \\
\hline 1 & 7 & 5 & 5 & 3 & 1 & \\
\hline 2 & 6 & 5 & 5 & 3 & 1 & \\
\hline 3 & 7 & 6 & 5 & 3 & 2 & \\
\hline 4 & 7 & 6 & 6 & 4 & 2 & \\
\hline 5 & 5 & 6 & 4 & 5 & 2 & \\
\hline 6 & 5 & 6 & 4 & 4 & 3 & \\
\hline 7 & 6 & 6 & 5 & 4 & 4 & \\
\hline 8 & 6 & 7 & 3 & 3 & 2 & \\
\hline 9 & 6 & 6 & 4 & 3 & 2 & \\
\hline 10 & 6 & 6 & 4 & 3 & 3 & \\
\hline 11 & 7 & 5 & 4 & 3 & 1 & \\
\hline 12 & 7 & 5 & 4 & 3 & 1 & \\
\hline Average & 6.25 & 5.75 & 4.42 & 3.42 & 2.00 & 21.83 \\
\hline Degree of importance & 0.29 & 0.26 & 0.20 & 0.16 & 0.09 & 1.00 \\
\hline
\end{tabular}

Finally, calculate the ultimate importance of alternative frame shaped and severity of the desired words. The following is a calculation method.

An example of mixed-shaped type:

Degree of importance $=$ Degree of importance of desire word (Cute)

$\times$ Degree of importance of alternative (Cute)

+ Degree of importance of desire word (Urban)

$\times$ Degree of importance of alternative (Urban)

+ Degree of importance of desire word (Futuristic)

$\times$ Degree of importance of alternative (Futuristic)

Calculate diamond, staggered, loop, also U-shaped in the same way. Table 4 shows the results. Both the "mixed shape" and "loop shape" received a maximum score of 0.28 in the analysis results. In the preference 
study, subjects said that they liked the crossed portions of the mixed shape and the round lines of the loop shape. Based on these results, we selected these two shapes as alternatives.

\section{Frame Angle/Height}

For frame angle, we designated top tubes I and II as areas where we could make changes to the parameters. We used three standard angle/height values for each tube, yielding a total of nine options. Type I had the highest score in the analysis results, so we used it as our alternative for frame angle and height.

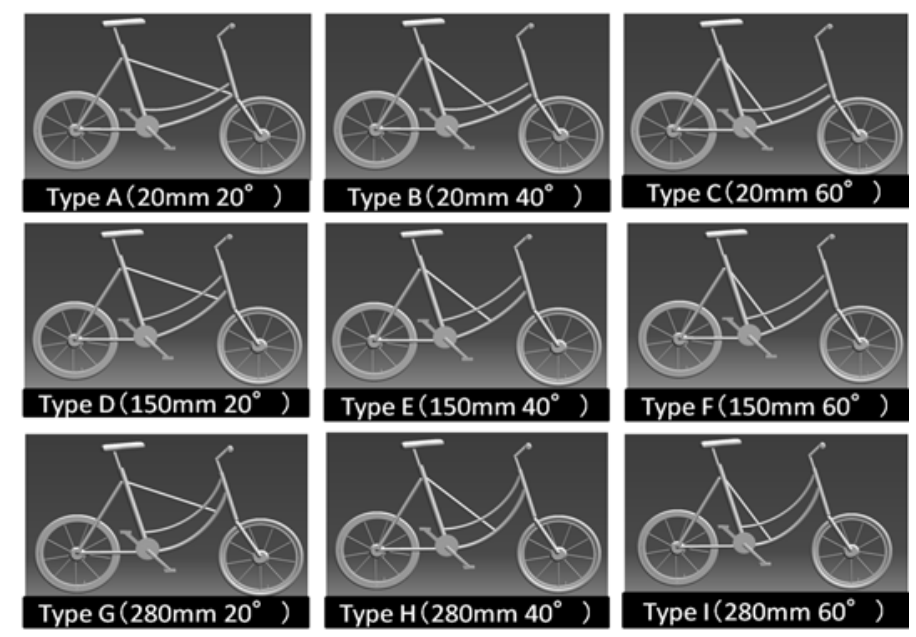

Figure 9. A survey of the position/angle of the bicycle frame by a CAD image.

\section{Color of the Frame/Tire}

We selected (1) frame of 12 colors; and (2) tire of 12 colors for a total of 144 color combinations, and created an image of each one using CAD. In doing a color analysis, we conducted a preference study on the lighter tones that women in the "girly" style category preferred. The color types used included five basic colors (Red, Yellow, Green, Blue, Violet) and five intermediate colors (yellow red, yellow green, blue green, blue violet, violet red), plus white (the brightest color) and black (the darkest color) for a total of 12 colors.

Using the frame and tire color combination analyses, we came up with 144 alternatives. The analysis indicated that the bicycles with (1) a white frame and blue tires; and (2) a white frame and red tires received the highest score of 0.0121 , so these were selected as alternatives.

\section{A Preference Study That Frame Color/Tire Color Combination Analysis}

Two bicycle types were selected as a result of the frame color/tire color combination analysis: (1) a bicycle with a white frame and blue tires; and (2) a bicycle with a white frame and red tires. A preference study was then done on this frame color with different front-rear tire color combinations. Type IV bicycle with a white frame, red front tire, and the blue back tire got the highest score of 0.36 , so it was selected as the alternative for this study.

\section{Create a Design}

The desire words identified in the analysis (cute, urban, and futuristic/fresh) were found to be linked to the selected bicycle parts, indicating that the bicycle design accurately reflected what women in the "girly" style category said they preferred as shown in Figure 10. 


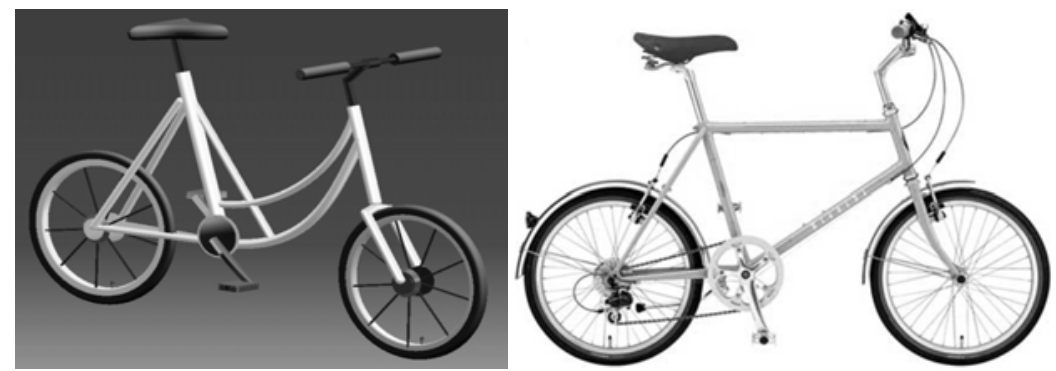

Figure 10. Bicycle embodying and bicycle for verification comparison.

\section{Verification}

Using the CAD model of the bicycle, women in the "girly" style category were asked to rate how cute, urban, and futuristic/fresh it seemed using a seven-point scoring system. The results indicated that the study produced the appropriate design results. The bicycle for comparative verification was chosen based on the preference studies, where it received the highest average evaluation from respondents among all 20 small-wheeled bicycles as shown in Figure 10.

The bicycles used for comparison all received a favorable evaluation score of about four, while the bicycle created in this study received an evaluation of about five. The verification thus indicated that our bicycle design achieved its intended goal of expressing a certain image and sensibility. In order to evaluate and verify the research project as a whole, an interview survey was conducted at an actual design center at Fortune bike to see what people there thought of the research results. Participants pointed out that the model in the study would give them the ability to quantify and examine preference free from preconceptions, allowing designers and front-line staff to better exchange information.

In addition, participants pointed out that the ability to identify focal points during the eye-tracking camera study as a way to identify the areas of the bicycle with the most impact made it possible to change or create designs in a logical manner. One respondent offered constructive feedback, suggesting that we verify the results with an actual bicycle rather than a CAD model. In this way, the approach model developed in this study was confirmed to be effective. The result is shown in Figure 11.

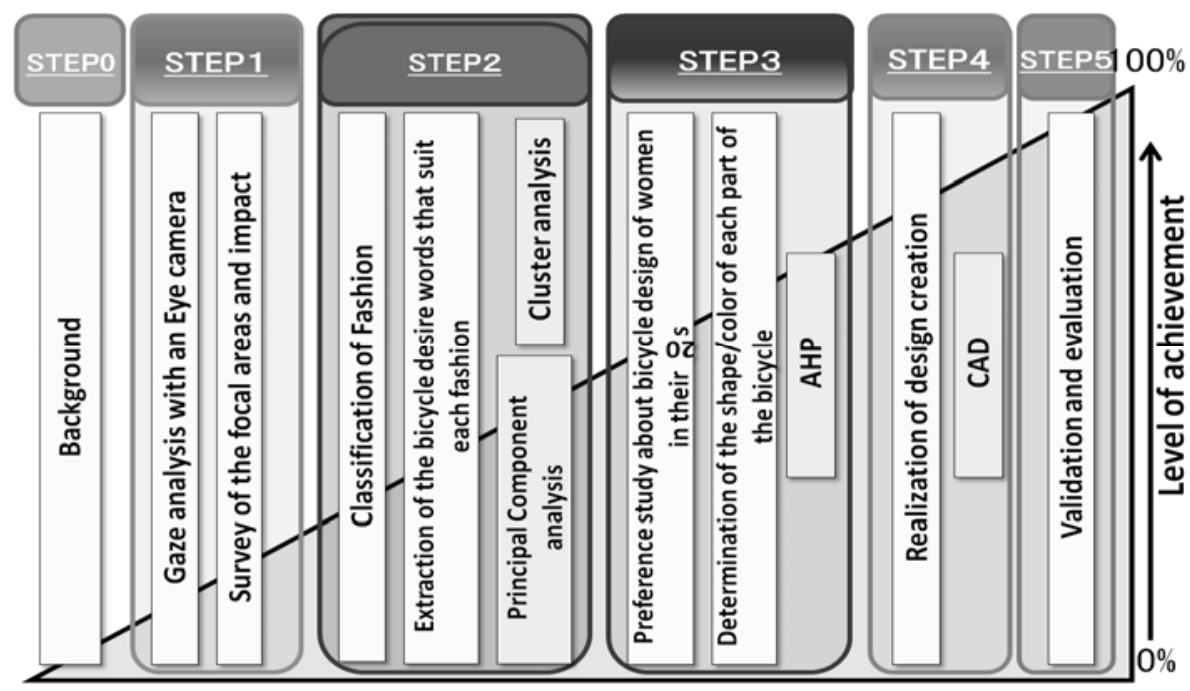

Figure 11. The bicycle design approach model completed. 


\section{Conclusions}

This study aimed to set up a bicycle design approach model that would resolve some of the issues that bicycle designers face, creating a bicycle design that reflected the preferences of women in their 20s with a "girly" fashion style (Koizumi et al., 2012b). Ideas for future research include increasing the areas of the bicycle that are studied, designing using different parameters, applying the design approach model developed here to different age and preference groups, and designing an actual bicycle based on the model.

\section{References}

Amasaka, K. (2002a). New JIT, a new management technology principle at Toyota. International Journal of Production Economics, 80, 135-144.

Amasaka, K. (2002b). Reliability of oil seal for transaxle-A science SQC approach at Toyota. Case Studies in Reliability and Maintenance (pp. 571-588). New Jersey: John Wiley \& Sons, Inc..

Amasaka, K. (2003). A “dual total task management team” involving both Toyota and NOK-A cooperative team approach for reliability improvement of transaxle. Proceedings from the Group Technology/Cellular Manufacturing World Symposium (pp. 265-270), Columbus, Ohio.

Amasaka, K. (2005). Constructing a customer science application system "CS-CIANS”-Development of a global strategic vehicle "Lexus” utilizing new JIT. WSEAS Transactions on Business and Economics, 3(2), 135-142.

Amasaka, K. (2007a). The validity of advanced TMS, a strategic development marketing system utilizing new JIT. International Business and Economics Research Journal, 6(8), 35-42.

Amasaka, K. (2007b). The validity of "TDS-DTM”, a strategic methodology of merchandise-Development of new JIT, key to the excellence design "LEXUS”. International Business and Economics Research Journal, 6(11), 105-115.

Amasaka, K. (2007c). The validity of advanced TMS, a strategic development marketing system utilizing new JIT. International Business and Economics Research Journal, 6(8), 35-42.

Amasaka, K. (2008a). Science TQM, a new quality management principle: The quality management strategy of Toyota. The Journal of Management and Engineering Integration, 1(1), 7-22.

Amasaka, K. (2008b). Strategic QCD studies with affiliated and non-affiliated suppliers utilizing new JIT. Encyclopedia of Networked and Virtual Organizations, III, 1516-1527.

Amasaka, K. (2009b). An intellectual development production hyper-cycle model-New JIT fundamentals and applications in Toyota. International Journal of Collaborative Enterprise, 1(1), 103-127.

Amasaka, K., Nagaya, A., \& Shibata, W. (1999). Studies on design SQC with the application of science SQC-Improving of business process method for automotive profile design. Japanese Journal of Sensory Evaluations, 3(1), 21-29.

Amasaka, K., Watanabe, M., \& Shimakawa, K. (2005). Modeling of strategic marketing system to reflect latent customer needs and its effectiveness. The Magazine of Research \& Development for Cosmetics, Toiletries \& Allied Industries, 33(1), 72-77.

Gabor, A. (1990). The man who discovered quality: How Deming W. E. brought the quality revolution to America. New York: Random House, Inc..

Joiner, B. L. (1994). Forth generation management: The new business consciousness. New York: Joiner Associates, Inc..

Koizumi, K., Kawahara, S., \& Kizu, Y. (2011). Research of the bicycle design approach model in consideration of the fashion by statistical science and cad-an example about women in their 20s (Graduation thesis).

Koizumi, K., Kawahara, S., \& Kizu, Y. (2012a). A bicycle design model based on young women's fashion combined with CAD and statistical science (Graduation thesis).

Koizumi, K., Kawahara, S., \& Kizu, Y. (2012b). A bicycle design model based on young women’s fashion combined with CAD and statistical science (Graduation thesis).

Mary, W. (1988). The deming management method. New York: Dodd, Mead \& Company, Inc..

Shewhart, W. A. (1986). Statistical method from the viewpoint of quality control. New York: Dover Publications, Inc.. 